\title{
Etiological profile of visual impairment in children
}

\author{
Pragati Garg1,*, Ritika Mullick ${ }^{2}$ \\ ${ }^{1}$ Professor and HOD, ${ }^{2}$ Junior Resident, Dept. of Ophthalmology, Era's Lucknow Medical College and Hospital, Uttar Pradesh, \\ India
}

*Corresponding Author:

Email: drpragati89@gmail.com

\begin{abstract}
Introduction: Vision 2020 - the right to sight programme is a global initiative to eliminate avoidable blindness worldwide by the year 2020. The control of blindness in children is one of the priority areas of the World Health Organization's Vision 2020.

The aim of this study was to identify the major causes of visual impairment in children and to identify the avoidable, i.e. readily preventable or treatable, causes of severe visual impairment/ blindness.

Materials and Methods: It was an observational cross sectional study, conducted in the Out Patient Department (OPD) of an ophthalmology unit of a tertiary hospital in northern India between; June 2012 to May 2017.

The study population was all new patients aged 16 years and younger. 1543 children $<16$ years of age were recruited for the study.

A detailed history was elicited. Refraction was performed as and when required. Anterior segment examination was done with torch and slit lamp. Posterior segment examination was performed using direct and indirect ophthalmoscopy.

Results: Among the study population, $54.2 \%$ were females with a Female: Male ratio of 1.18:1. Maximum numbers of children were of the age group of 12-15yrs.

Anatomical sites affected in these patients were whole globe (microphthalmos, anophthalmos, phthisis) in $3.5 \%$, cornea (staphyloma, scar) $11 \%$, retina (dystrophy, post inflammatory retinal scarring and retinopathy of prematurity) $6.5 \%$, lens $37 \%$.

Maximum number of cases having visual impairment due to lenticular causes (cataract, aphakia, pseudophakia) and others (Refractive errors including High Pathological Myopia, Strabismus, Ptosis)were seen in the age group 12-15yrs. ( $p<0.001)$, while retinal and uveal (coloboma) disorders were significantly affecting the younger age groups of $0-3$ years and $4-7 \mathrm{yrs}(\mathrm{p}<0.0001)$.

Refractive errors included cases of myopia, hypermetropia and astigmatism.

Conclusion: Although most ocular lesions are preventable but due to ignorance and carelessness of being not attended to, they cause impairment of vision or even blindness.

Our findings can be of great assistance to existing school eye health programmes that are focusing mainly on the problems of refractive errors in children.
\end{abstract}

Keywords: Blindness, Children, Etiology.

\section{Introduction}

Vision 2020 - the right to sight programme is a global initiative to eliminate avoidable blindness worldwide by the year 2020. The control of blindness in children is one of the priority areas of the World Health Organization's Vision 2020.

The problem of childhood blindness is greatest in the developing nations of Asia and Africa where the prevalence of blindness in children (under 16 years) is estimated to be 5 times as high as in the United Kingdom. ${ }^{1}$

This age group is also considered a priority as severe visual loss in children can affect their development, mobility, education, and employment opportunities and this in general impairs the quality of life, which has a direct effect on the economic health of the nation as well in terms of gross domestic product (GDP). ${ }^{2}$

Childhood blindness is second only to cataract in terms of blind years.

Blindness in children ranges from approximately $0.3 / 1000$ children in affluent regions to $1.5 / 1000$ in the poorest communities. ${ }^{3}$ Globally there are estimated to be 1.4 million blind children, almost three quarters of whom live in developing countries. ${ }^{4}$ The population of
India in 2011 was estimated to be 1.21 billion, approximately 400 million of whom are children under 16 years of age $(33.05 \%) .{ }^{5}$ Overall, there are probably 280 000-320 000 blind children in India.

About $30 \%$ of blind population of India loses their eyesight before the age of 20 years and many of them are under five when they become blind. ${ }^{6} 50 \%$ of the childhood blindness is preventable. ${ }^{7}$ Considering the fact that $30 \%$ of India's blind population loses their sight before the age of 20 years, the importance of early detection and treatment of ocular diseases and visual impairment in young is obvious.

Children are affected by various eye disorders like refractive errors, squint, vitamin A deficiency and eye infections. Uncorrected refractive errors form one of the important causes of visual impairment and blindness in most developing countries including India. This along with vitamin A deficiency forms a major preventable cause of blindness in the young age group.

The aim of this study was to identify the major causes of visual impairment in children and to identify the avoidable, i.e. readily preventable or treatable, causes of severe visual impairment/ blindness (SVI/BL). 


\section{Materials and Methods}

It was an observational cross sectional study, conducted in the Out Patient Department (OPD) of an ophthalmology unit of a tertiary hospital in northern India between June 2008 to May 2013.

The study population was all new patients aged 16 years and younger. The study techniques were record analysis and a full ophthalmic evaluation by consultant ophthalmologists. 1543 children $<16$ years of age were recruited for the study after the informed consent of their parents and also after getting the ethical clearance.

History was taken regarding the ocular complaints: with special reference to visual loss, use of spectacles, any ocular surgical intervention, intrauterine and perinatal history, dietary intake, ocular trauma and any systemic disease 1000 children, aged 0-15 years, who had corrected visual acuity (VA) less than $6 / 18$ in the better eye after medical or surgical treatment, were included in the study while the remaining 543 children with visual acuity more than $6 / 18$ in the better eye were excluded. Refraction was performed as and when required. Anterior segment examination was done with torch and slit lamp. Posterior segment examination was performed using direct and indirect ophthalmoscopy.

The WHO/PBL eye examination record for children with blindness and low vision was used to categorise the causes of blindness and to record findings, using the definitions in the coding instructions. ${ }^{8,9}$

The age at presentation, sex and clinical diagnosis were determined from records. The clinical diagnosis was grouped as diseases of different parts of eye and WHO classification was used to express different types of ocular morbidity.

Patients were categorized into three segments on the basis of age (0-3 years, 4-11 years, and 12-15 years). Results were statistically analyzed and chi square tests were applied to find out the significance.

\section{Results}

A total of over one lac patients attended the OPD and emergency under the ophthalmology unit of which 1000 ( $<16$ years. of age) fulfilled the inclusion criteria. Among the study population, $54.2 \%$ were females with a Female: Male ratio of 1.18:1. Maximum numbers of children were of the age group of 12-15 years.

Anatomical sites affected in these patients were whole globe (microphthalmos, anophthalmos, phthisis) in $3.5 \%$, cornea (staphyloma, scar) $11 \%$, retina (dystrophy, post inflammatory retinal scarring and retinopathy of prematurity) $6.5 \%$, lens $37 \%$ (Table 1). Most common structure affected was lens in all the age groups followed by cornea $(p<0.0001)$. Maximum number of cases having visual impairment due to lenticular causes (cataract, aphakia, pseudophakia) and others (Refractive errors including high pathological myopia, strabismus, ptosis) were seen in the age group $12-15$ years. $(\mathrm{p}<0.001)$, while retinal and uveal (coloboma) disorders were significantly affecting the younger age groups of 0-3 years and 4-7 years. $(\mathrm{p}<0.0001)$ (Table 2). The underlying cause of visual loss was undetermined in 55\% children, (Male $-26.8 \%$, Female-28.2\%) while childhood disorders were responsible in 39.5\%, (Male-16.2\%, Female-23.3\%) (Table 3).

Refractive errors included cases of myopia, hypermetropia and astigmatism, and were found to be the most common cause of visual impairment in our study $(25 \%) 9.9 \%$ in males and $15.1 \%$ in females.

Retinal pathology was responsible for visual impairment maximally in the age group 0-3 years. $(p<0.001)$. Under childhood factors the most common cause was vitamin A deficiency followed by meningitis in both males $(p<0.04)$ and females $(p<0.0001)$. Childhood factors were the most significant cause of visual impairment amongst all the age groups $(\mathrm{p}<0.001)$. (Table 4)

Table 1: Visual impairment etiology as related to anatomical site

\begin{tabular}{|c|c|c|c|c|c|c|}
\hline \multirow[t]{2}{*}{ Anatomical Site } & \multicolumn{2}{|c|}{$\mathbf{M}$} & \multicolumn{2}{|c|}{$\mathbf{F}$} & \multirow[t]{2}{*}{ Chi sq } & \multirow[t]{2}{*}{ P value } \\
\hline & No. & $\%$ & No. & $\%$ & & \\
\hline \multicolumn{7}{|l|}{ Whole Globe } \\
\hline Microphthalmos & 4 & 0.4 & 6 & 0.6 & 0.142 & 0.707 \\
\hline Anophthalmos & 3 & 0.3 & 7 & 0.7 & 1.028 & 0.311 \\
\hline Phthisis & 5 & 0.5 & 10 & 1.0 & 0.968 & 0.325 \\
\hline \multicolumn{7}{|l|}{ Cornea } \\
\hline Staphyloma & 7 & 0.7 & 3 & 0.3 & 2.363 & 0.124 \\
\hline Scar & 46 & 4.6 & 54 & 5.4 & 0.004 & 0.983 \\
\hline \multicolumn{7}{|l|}{ Lens } \\
\hline Cataract & 96 & 9.6 & 104 & 10.4 & 0.444 & 0.505 \\
\hline Aphakia & 24 & 2.4 & 46 & 4.6 & 4.089 & 0.043 \\
\hline Pseudophakia & 58 & 5.8 & 42 & 4.2 & 6.551 & 0.01 \\
\hline \multicolumn{7}{|l|}{ Retina } \\
\hline Dystrophy & 18 & 1.8 & 12 & 1.2 & 2.476 & 0.116 \\
\hline $\begin{array}{l}\text { Post inflammatory } \\
\text { retinal scarring }\end{array}$ & 8 & 0.8 & 12 & 1.2 & 0.286 & 0.593 \\
\hline ROP & 6 & 0.6 & 4 & 0.4 & 0.809 & 0.369 \\
\hline Albinism & 4 & 0.4 & 1 & 0.1 & 2.353 & 0.125 \\
\hline
\end{tabular}




\begin{tabular}{|l|c|c|c|c|c|c|}
\hline UVEA & & & & & & \\
\hline Coloboma & 28 & 2.8 & 17 & 1.7 & 5.055 & 0.025 \\
\hline Optic Nerve & & & & & & \\
\hline Atrophy & 34 & 3.4 & 41 & 4.1 & 0.01 & 0.918 \\
\hline Glaucoma & & & & & & \\
\hline Buphthalmos & 12 & 1.2 & 8 & 0.8 & 1.634 & 0.201 \\
\hline Others & 99 & 9.9 & 151 & 15.1 & 5.328 & 0.021 \\
\hline $\begin{array}{l}\text { Refractive Errors } \\
\text { (including High } \\
\text { Pathological Myopia) }\end{array}$ & & & & & & \\
\hline Strabismus & 3 & 0.4 & 16 & 1.6 & 5.513 & 0.019 \\
\hline Ptosis & 459 & 45.9 & 541 & 54.1 & & 0.311 \\
\hline
\end{tabular}

Table 2: Visual impairment etiology as related to age

\begin{tabular}{|l|c|c|c|c|c|c|c|c|c|c|}
\hline $\begin{array}{c}\text { Anatomical } \\
\text { Site }\end{array}$ & \multicolumn{2}{|c|}{$\mathbf{0 - 3}$ years. } & \multicolumn{2}{c|}{$\mathbf{4 - 7}$ years. } & \multicolumn{2}{c|}{$\mathbf{8 - 1 1}$ years. } & \multicolumn{2}{c|}{$\mathbf{1 2 - 1 5}$ years. } & Chi sq. & p value \\
\hline & No. & $\%$ & No. & $\%$ & No. & $\%$ & No. & $\%$ & & \\
\hline Whole Globe & 9 & 0.9 & 12 & 1.2 & 9 & 0.9 & 5 & 0.5 & 10.77 & 0.013 \\
\hline Cornea & 23 & 2.3 & 32 & 3.2 & 35 & 3.5 & 20 & 2 & 16.39 & 0.001 \\
\hline Lens & 45 & 4.5 & 51 & 5.1 & 126 & 12.6 & 148 & 14.8 & 24.67 & $<0.001$ \\
\hline Retina & 21 & 2.1 & 19 & 1.9 & 13 & 1.3 & 12 & 1.2 & 25.36 & $<0.001$ \\
\hline Optic Nerve & 16 & 1.6 & 19 & 1.9 & 21 & 2.1 & 19 & 1.9 & 5.4 & 0.145 \\
\hline UVEA & 12 & 1.2 & 16 & 1.6 & 7 & 0.7 & 10 & 1 & 15.41 & 0.002 \\
\hline Glaucoma & 3 & 0.3 & 10 & 1 & 4 & 0.4 & 3 & 0.3 & 11.35 & 0.01 \\
\hline Others & 18 & 1.8 & 48 & 4.8 & 98 & 9.8 & 116 & 11.6 & 28.71 & $<0.001$ \\
\hline & 144 & 14.4 & 207 & 20.7 & 313 & 31.3 & 334 & 33.4 & & \\
\hline
\end{tabular}

Table 3: Visual impairment etiology as related to time of visual loss

\begin{tabular}{|l|c|c|c|c|c|c|}
\hline \multicolumn{1}{|c|}{ Etiology } & \multicolumn{2}{c|}{ M } & \multicolumn{2}{c|}{ F } & Chi Sq & p-value \\
\hline Intrauterine Factors & No. & $\%$ & No. & $\%$ & & \\
\hline Rubella & & & & & & \\
\hline Perinatal Factors & 9 & 0.9 & 16 & 1.6 & 1.96 & 0.162 \\
\hline ROP & & & & & & \\
Neonatal Meningitis & 6 & 0.6 & 4 & 0.4 & 0.4 & 0.527 \\
Ocular trauma during birth & 6 & 0.6 & 4 & 0.3 & 1 & 0.317 \\
\hline Childhood Factors & 7 & 0.7 & 3 & 0.5 & 0.333 & 0.564 \\
\hline Vitamin A deficiency & 70 & & & & & \\
Meningitis & 52 & 5.2 & 450 & 15 & 29.091 & $<0.0001$ \\
Trauma & 40 & 4 & 35 & 4.8 & 0.61 & 0.689 \\
\hline Undetermined & & & & & & \\
\hline Cataract & 47 & 4.7 & 33 & 3.3 & 2.45 & 0.118 \\
Glaucoma & 12 & 1.2 & 8 & 0.8 & 0.8 & 0.371 \\
Abnormality since birth & 23 & 2.3 & 27 & 2.7 & 0.32 & 0.572 \\
Others & 186 & 18.6 & 214 & 21.4 & 1.96 & 0.162 \\
\hline & 458 & 45.8 & 542 & 54.3 & 7.056 & 0.008 \\
\hline
\end{tabular}

Table 4: Visual impairment etiological factors as related to child's age

\begin{tabular}{|l|c|c|c|c|c|c|c|c|c|c|}
\hline \multicolumn{1}{|c|}{ Etiology } & \multicolumn{2}{c|}{ 0-3 years. } & \multicolumn{2}{|c|}{ 4-7 years. } & \multicolumn{2}{c|}{ 8-11 years. } & \multicolumn{1}{c|}{ 12-15 years. } & Chi sq. & P value \\
\hline & No. & $\%$ & No. & $\%$ & No. & $\%$ & No. & $\%$ & & \\
\hline Intrauterine factors & 14 & 1.4 & 3 & 0.3 & 5 & 0.5 & 3 & 0.3 & 24.73 & $<0.001$ \\
\hline Perinatal factors & 12 & 1.2 & 7 & 0.7 & 6 & 0.6 & 5 & 0.5 & 11.25 & 0.01 \\
\hline Childhood Factors & 70 & 7 & 81 & 8.1 & 123 & 12.3 & 126 & 12.6 & 0.049 & 0.921 \\
\hline Undetermined & 87 & 8.7 & 113 & 11.3 & 163 & 16.3 & 182 & 18.2 & 4.88 & 0.181 \\
\hline & 183 & 18.3 & 204 & 20.4 & 297 & 29.7 & 316 & 31.6 & & \\
\hline
\end{tabular}

\section{Discussion}

In the present study, the various ophthalmic disorders were assessed in the study subjects of 1000 children which consisted of $458(45.8 \%)$ males and 542
(54.2\%) females with a F:M ratio of 1.18:1. This ratio was against the findings of Sethi $\mathrm{S}$ et al which consisted of $60.6 \%$ males and $39.1 \%$ female patients. It maybe because, most of our patients were of rural background 
and in such backgrounds, the parents were least observant in cases of female child. In our study, the highest frequency of consultation was seen in the age group of 12-15 years, similar to the findings of Onokpoya et all study (11-15 years). ${ }^{10}$

Here results may vary slightly from population based study as only the children attending the OPD were incorporated.

Refractive errors and cataract were the most common preventable causes of severe visual impairment (25\% and 20\% respectively). Vitamin A deficiency was an important contributing factor in many cases leading to keratomalacia and blindness. Although it is difficult to specifically ascertain the aetiology of corneal scarring several years after the original pathology, vitamin A deficiency appears to be the major cause as in majority of children with corneal scarring, diarrhea, or measles (which can precipitate acute vitamin A deficiency) preceded the onset of visual loss.

Ignorance of visual impairment due to cataract, with the delay in its management was another contributing factor for severe visual impairment. Uncorrected refractive error was the second commonest morbid condition (25\%) comparable to the study by Jayant D and Malathi $\mathrm{K}$ in rural Maharashtra ${ }^{11}$ and Mahapatra et al at Bhubaneshwar. ${ }^{12}$

The children having visual impairment due to intrauterine and perinatal factors reported early and so was more commonly seen in younger age group of 0-7 years while childhood factors and undetermined factors were more common causes for visual impairment in older age group of 8-15 years.

Congenital abnormalities of the globe (microphthalmos, anophthalmos and coloboma) were responsible for $6.5 \%$ of SVI/Blindness. These results are lesser than that reported in Karnataka (28.7\%) and Tamil Nadu (20.6\%). ${ }^{13}$ Congenital anomalies are maybe due to genetic disorders or intrauterine factors but in majority the etiology is unknown. The association between Vaccine associated diseases and congenital anomalies, including microphthalmos was also observed by Rahi. ${ }^{14}$

The presence of a large proportion of children with visual loss of unknown aetiology is consistent with results from other studies using similar methods and reflects the limited investigations available and the lack of examination of family members in many cases. For example, congenital cataracts may have much varied aetiology and in the absence of a positive family history or signs consistent with congenitally acquired rubella syndrome they were classified as being of unknown aetiology.

\section{Conclusion}

Although most ocular lesions are preventable, but due to ignorance and carelessness of being not attended to, they cause impairment of vision or even blindness.
Data on the pattern of presentation of childhood eye diseases serve as useful template for planning ophthalmic care strategies for children in a given region. Our findings can be of great assistance to existing school eye health programmes that are focusing mainly on the problems of refractive errors in children. These findings will be useful for ophthalmic care planning and can serve as a baseline for the development of a paediatric ophthalmic subspeciality in the tertiary hospital.

There has been a renewed interest in improving primary health care. Primary healthcare programs should include services such as eye examination at birth, eye screening of preschool/school children, early management of congenital cataract, vaccination for infectious diseases in children, initiatives to train health workers, and finally cooperation between pediatricians and ophthalmologists.

Strategies to combat childhood blindness require accurate, standardized data on the causes. Health policy planning and implementation occur at central and state level. Information on the causes of childhood blindness needs to identify the important causes by state in order to target limited resources to the most important priorities.

\section{References}

1. Foster A, Gilbert CE. Epidemiology of childhood blindness. Eye. 1992;6(Pt 2):173-176.

2. Jose R., Rathore AS Rajashekhar V, Sachdeva S. National programme for control of blindness (NPCB) in the eleventh (11) five year plan period. Community eye health journal 2008;21:S115-S116.

3. World Health Organization. Preventing blindness in children. Report of a WHO/IAPB scientific meeting. WHO/PBL/00.71. Geneva: WHO, 2000.

4. Anon. Blindness in the world. Surv Ophthalmol. 2000;45 (Suppl.):s21-31.

5. Census of India 2001. India: Registrar General and Census Commissioner, 2001.

6. Danish Assistance to the National Programme for Control of Blindness. New Delhi. India: Vision screening in school children. Training module.1.

7. Rahi JS, Sripathi S, Gilbert CE, et al. Childhood blindness in India: causes in 1318 blind school studies in nine states. Eye. 1995;9(Pt 5):545-550.

8. Parsons' Diseases of the Eye. 20th ed. New Delhi: Elsevier;2007:530-531.

9. Gilbert CE, Foster A, Thylefors B, et al. Childhood blindness - a new form for recording causes of visual loss in children. Bull World Health Organ. 1993;71(5):485489.

10. ICEH. Coding Instructions. WHO/PBL eye examination record for children with blindness and low vision. London: ICEH.

11. Onakpoya OH, Adeoye AO. Childhood eye diseases in southwestern Nigeria: a tertiary hospital study. Clinics. 2009;64(10):947- 952.

12. Deshpande Jayant D, Malathi K. Prevalence of ocular morbidities among school children in rural area of North Maharashtra in India. National Journal of Community Medicine. 2011;2(2):249-254. 
13. S Mahapatro, MK Das, GK Padhy, SS Kar, AK Nanda. Prevalence of ocular disorders in school children in rural area surrounding Bhubanesar. J Com Med. 2010;6(1):5.

14. SJ Horney's, Adolph K Gothwal, L Dandona, A Foster. Evaluation of children in six blind schools of Andhra Pradesh. Indian J Ophthalmol. 2000;48(3):195-200.

15. Rahi JS, Sripathi S, Gilbert CE, Foster A. Childhood blindness due to vitamin A deficiency in India: Regional variations. Arch Dis Child. 1995;72(4):330-333.

How to cite this article: Garg P, Mullick R. Etiological profile of visual impairment in children. Ind J Clin Exp Ophthalmol. 2018;4(3):363-367. 